\title{
Probabilistic risk assessment for personal exposure to carcinogenic polycyclic aromatic hydrocarbons in Taiwanese temples
}

\author{
Chung-Min Liao *, Kuo-Chih Chiang \\ Ecotoxicological Modeling Center, Department of Bioenvironmental Systems Engineering, National Taiwan University, \\ Taipei 10617, Taiwan, ROC
}

Received 4 March 2005; received in revised form 1 August 2005; accepted 18 August 2005

Available online 15 November 2005

\begin{abstract}
To assess how the human exposure to airborne carcinogenic polycyclic aromatic hydrocarbons (PAHs) during working in or visiting a typical Taiwanese temple, we present a probabilistic risk model, appraised with reported empirical data. Two approaches are applied, one based on animal-derived benzo $[a]$ pyrene $(\mathrm{B}[a] \mathrm{P})$ toxic equivalents $\left(\mathrm{B}[a] \mathrm{P}_{\text {eq }}\right)$ of individual PAHs and one is assumed that the potency of PAH mixtures is linked to their $\mathrm{B}[a] \mathrm{P}$ level. The model integrates probabilistic exposure profiles of total-PAH and particle-bound PAH levels inside a temple from a published exploratory study with probabilistic incremental lifetime cancer risk (ILCR) models taking into account inhalation and dermal contact pathways, to quantitatively estimate the exposure risks for three age groups of adult, adolescent, and child. Risk analysis indicates that $90 \%$ probability inhalation ILCRs for three age groups have orders of magnitude around $10^{-7}-10^{-6}$; whereas for the dermal contact ILCRs ranging from $10^{-5}$ to $10^{-4}$, indicating high potential cancer risk. All $90 \%$ probabilities of $\mathrm{B}[a] \mathrm{P}$ - and $\mathrm{B}[a] \mathrm{P}_{\text {eq }}$-based total ILCRs are larger than $10^{-6}$, indicating unacceptable probability distributions for three age groups. Sensitivity analysis indicates that to increase the accuracy of the results efforts should focus on a better definition of probability distributions for inhalation cancer slope factor, inhalation rates, and particlebound PAH-to-skin adherence factor. We estimate risk-based visiting frequency advice for adult, adolescent, and child to a temple ranging from 5 to 7,17 to 23 , and 48 to $65 \mathrm{year}^{-1}$, respectively, based on an average $3 \mathrm{~h}$ residence time. (c) 2005 Elsevier Ltd. All rights reserved.
\end{abstract}

Keywords: Temple; Incense; Polycyclic aromatic hydrocarbons; Benzo[a]pyrene; Potency equivalency factor; Probabilistic risk assessment; Carcinogenicity

\section{Introduction}

There are tens of thousands of temples throughout the Taiwan Island in that only approximated 7500 of

\footnotetext{
* Corresponding author. Tel.: +88622363 4512; fax: +8862 23626433.

E-mail address: cmliao@ntu.edu.tw (C.-M. Liao).
}

the larger temples are officially registered (http://www. moi.gov.tw/stat/). It has been estimated that there are at least 20000-30000 temples with a construction size larger than or equal to an ordinary household in Taiwan. On religious dates, most of the larger temples are crowded with visitors. Burning incense inside the Buddhism and Taoism temples is an essential ceremonial practice in the Buddhism and Taoism tradition, 
performed by all worshippers from the pupils to the elders in that incense burning produces non-stop smoke during the long, slow, and incomplete combustion process. Some people have experienced acute irritation of the upper respiratory tract or coughing after such exposure (Lung et al., 2003). The public health risk assessment of this religious practice is worthy of attention.

It was found that carcinogenic polycyclic aromatic hydrocarbons (PAHs) were in the smoke of several ingredients of joss sticks (Tseng, 1996). Lin et al. (2002) has also found that the composition of PAHs emitted from incense burning varies greatly due to differences in the raw materials used in incense making. Lung et al. (2003) indicated that contribution of incense burning to indoor exposure concentrations of particle-bound PAHs ranged from 88 to $450 \mathrm{ng} \mathrm{m}^{-3}$. Lin et al. (2002) demonstrated that indoor and outdoor mean total PAHs in a selected temple were measured to be 6258 and $231 \mathrm{ng} \mathrm{m}^{-3}$, respectively, in that median values for indoor/outdoor ratios of individual PAHs ranged from 5.7 to 387.9 , implying that the temple was a significant PAH source.

Boffetta et al. (1997) demonstrated that human cancer causes of skin, lungs, and bladder have always been associated with PAHs. Armstrong et al. (2004) pointed out that the relationship between cancer and the environment is largely conditioned by investigations involving PAH exposures. Several individual PAHs such as benzo $[a]$ pyrene $(\mathrm{B}[a] \mathrm{P})$, chrysene, indeno $[1,2,3-c, d]$ pyrene, and benzo[b]fluoranthene have produced carcinogenic, mutagenic, and genotoxic effects in animal experiments (Thyssen et al., 1981; Deutsch-Wenzel et al., 1983). Somers et al. (2002) have also found out that air pollution enriched with PAHs has been shown to induce heritable (paternal germ-line) mutations in mice. More recently, PAHs have been associated with elevated levels of DNA adducts (PAH-DNA adducts) and $\mathrm{p} 53$ mutations in persons who smoke or are exposed to PAH in the workplace and ambient air (Alexandrov et al., 2002; Gaspari et al., 2003). Li et al. (1996) indicated that PAH-DNA adducts formed by the carcinogen $\mathrm{B}[a] \mathrm{P}$ diol epoxide $(\mathrm{B}[a] \mathrm{PDE})$ have been linked to an increased risk of lung cancer. Perera et al. (2002) have also indicated that airborne PAHs have been implicated in human reproductive effects, PAH-DNA adducts in newborns as well as preterm birth and intrauterine growth restriction. $\mathrm{B}[a] \mathrm{P}$ has been shown to be carcinogenic by dermal application (ATSDR, 1990).

Despite the potential importance of PAH exposures to human health, remarkably little is known about air levels of PAHs in Taiwanese temples by which a potential health risk to people working in or visiting the temples may pose. Lin et al. (2002) have reported the relevant measurements of PAHs in a selected Taiwanese temple and these measurements were sufficiently high to cause concern for personal exposure to carcinogenic
PAHs in temples. We were stimulated to develop a probabilistic risk assessment framework to evaluate the carcinogenic risk from personal exposure to PAHs in temples.

The objectives of this study are twofold: (1) to conduct a cancer risk assessment of personal exposure to PAHs for people working in or visiting the temples, and (2) to determine risk-based visiting frequency advice and suggested amount of incense burning of different types of commonly used incense. In the process, we compared two quantitative risk assessment methods used for $\mathrm{PAH}$ mixtures, one based on $\mathrm{B}[a] \mathrm{P}$ concentration from reported data and one based on $\mathrm{B}[a] \mathrm{P}$ equivalent concentration from animal studies. We reanalyze published data of airborne PAHs measurements in a selected Taiwanese temple. Based on these concentration data, we attempt to calculate the contribution of the analyzed PAHs to the cancer risks taking into account inhalation and dermal contact exposure pathways. To determine overall uncertainty in predicted risks, the uncertainty resulting from the assessment of exposure is propagated through the risk characterization process using the Monte Carlo simulation.

\section{Materials and methods}

\subsection{Reanalysis of reported PAH data}

Thanks to the valuable exploratory study of characteristics of indoor/outdoor airborne PAHs of a Taiwanese temple from the previous researchers (Lin et al., 2002), concentrations of total-PAH, particle-bound $\mathrm{PAH}$, and individual PAH (particulate + gas phase) have a well-informed framework. Lin et al. (2002) selected a Taiwanese temple located in the suburban area of Tainan city in southern Taiwan as the study site. The temple is $10 \mathrm{~m}$ off the ground and has internal dimensions of $50 \mathrm{~m} \times 20 \mathrm{~m} \times 3.4 \mathrm{~m}$. Sampling was conducted from 9:00 am to 5:00 pm and from 9:00 am to 9:00 am the next day, respectively, for three sequential days. The reported measurements also included the relationship between incense composition and PAH emissions for three representative types of incense of aloe wood, Taiwan yellow, and Taiwan black incense that all burned in the temple on a daily basis. We have also adopted the researches from $\mathrm{Li}$ and Ro (2000) for $\mathrm{PAH}$ concentrations measured in five incense burning homes and in 14 mixed residential homes (including one smoking household, five incense burning households, and eight households without incense burning or smoking) in Taipei region and a traffic-source data in Tainan region from Lee et al. (1995) as our major database for a comparison study.

A useful tool for estimating of the health risk posed by multi-component PAH exposure is based on the use 
of the individual compound's potency equivalency factor $(\mathrm{PEF})$ relative to $\mathrm{B}[a] \mathrm{P}$ based on a $\mathrm{PEF}$ scheme developed by Collins et al. (1998). In a first step, a $\mathrm{B}[a] \mathrm{P}$ equivalent concentration $\left(\mathrm{B}[a] \mathrm{P}_{\mathrm{eq}}\right)$ is calculated by the multiplication of the individual PAH concentration by its PEF. The carcinogenic potency of all considered PAHs can then be estimated as the sum of each individual $\mathrm{B}[a] \mathrm{P}_{\text {eq. }}$. Table 1 lists the PAHs and the PEFs used in the calculation associated with the cancer evidence of individual PAH compound classified by International Agency for Research on Cancer (IARC, 1987) and US EPA (OEHHA, 1993). Nisbet and LaGoy (1992) and Collins et al. (1998) have summarized the assumptions underlying the use of the PEF approach to the calculation of exposure to PAHs.

\subsection{Human health exposure and risk model}

The risk-based approach takes into account the exposure pathways including inhalation exposure and dermal contact. Three age groups are considered: child (1-11 years), adolescent (12-17 years), and adult
(18-70 years). The incremental lifetime cancer risk (ILCR) for incidental inhalation is defined as:

$$
R_{\mathrm{I}}=\frac{C_{\mathrm{a}}\left(\mathrm{CSF}_{\mathrm{i}}\left(\frac{\mathrm{BW}}{70}\right)^{1 / 3}\right) \mathrm{IR}_{\mathrm{air}} \cdot \mathrm{EF} \cdot \mathrm{ED}}{\mathrm{BW} \cdot \mathrm{AT}} \times \mathrm{cf},
$$

where $R_{\mathrm{I}}$ is the incremental individual lifetime cancer risk associated with inhalation, $\mathrm{CSF}_{\mathrm{i}}$ is the inhalation carcinogenic slope factor $\left(\mathrm{mg} \mathrm{kg}^{-1} \mathrm{~d}^{-1}\right)^{-1}$, IR $\mathrm{IR}_{\text {air }}$ is the inhalation rate $\left(\mathrm{m}^{3} \mathrm{~d}^{-1}\right), C_{\mathrm{a}}$ is the air concentration of PAHs $\left(\mathrm{ng} \mathrm{m}^{-3}\right), \mathrm{EF}$ is the exposure frequency $\left(\mathrm{d}\right.$ year $\left.{ }^{-1}\right), \mathrm{ED}$ is the exposure duration (year), AT is the averaging time for carcinogens (d), BW is the body weight $(\mathrm{kg})$, and $\mathrm{cf}$ is the conversion factor $\left(10^{6}\right)$. We treated $C_{\mathrm{a}}, \mathrm{IR}_{\text {air }}, \mathrm{CSF}_{\mathrm{i}}, \mathrm{BW}$, and $\mathrm{EF}$ in Eq. (1) probabilistically.

The ILCR for dermal contact pathway is defined as

$$
R_{\mathrm{D}}=\frac{C_{\mathrm{pa}}\left(\mathrm{CSF}_{\mathrm{d}}\left(\frac{\mathrm{BW}}{70}\right)^{1 / 3}\right) \mathrm{AB} \cdot \mathrm{SA} \cdot \mathrm{EV} \cdot \mathrm{AF}_{\mathrm{d}} \cdot \mathrm{EF} \cdot \mathrm{ED}}{\mathrm{BW} \cdot \mathrm{AT}} \times \mathrm{cf},
$$

Table 1

\begin{tabular}{|c|c|c|c|}
\hline \multirow[t]{2}{*}{ Name with abbreviation } & \multicolumn{2}{|c|}{ Classification } & \multirow[t]{2}{*}{ PEF } \\
\hline & IARC $^{\mathrm{a}}$ & $\mathrm{US} \mathrm{EPA}^{\mathrm{b}}$ & \\
\hline \multicolumn{4}{|l|}{ Reference } \\
\hline Benzo $[a]$ pyrene $(\mathrm{B}[a] \mathrm{P})$ & $2 \mathrm{~A}$ & $\mathrm{~B} 2$ & 1 \\
\hline \multicolumn{4}{|l|}{$P A H s$} \\
\hline Acenaphthene (Acp) & & & 0.001 \\
\hline Acenaphthylene (AcPy) & & & 0.001 \\
\hline Anthracene (Ant) & 3 & $\mathrm{D}$ & 0.01 \\
\hline $\operatorname{Benzo}[a]$ anthracene $(\mathrm{B}[a] \mathrm{A})$ & $2 \mathrm{~A}$ & $\mathrm{~B} 2$ & 0.1 \\
\hline Benzo $[b]$ chrycene $(\mathrm{B}[b] \mathrm{C})$ & & & NA \\
\hline Benzo $[b]$ fluoranthene $(\mathrm{B}[b] \mathrm{FT})$ & $2 \mathrm{~B}$ & $\mathrm{~B} 2$ & 0.1 \\
\hline Benzo $[k]$ fluoranthene $(\mathrm{B}[k] \mathrm{FT})$ & 2B & $\mathrm{B} 2$ & 0.1 \\
\hline Benzo $[e]$ pyrene $(\mathrm{B}[e] \mathrm{P})$ & 3 & & $0.01^{\mathrm{c}}$ \\
\hline Benzo $[g, h, i]$ perylene $(\mathrm{B}[g, h, i] \mathrm{P})$ & 3 & $\mathrm{D}$ & 0.01 \\
\hline Chrysene (CHR) & 3 & $\mathrm{~B} 2$ & 0.01 \\
\hline Coronene (COR) & 3 & & $0.001^{\mathrm{c}}$ \\
\hline Cyclopenta $[c, d]$ pyrene $(\mathrm{C}[c, d] \mathrm{P})$ & 3 & & $0.1^{\mathrm{c}}$ \\
\hline Dibenzo $[a, h]$ anthracene $(\mathrm{DB}[a, h] \mathrm{A})$ & $2 \mathrm{~A}$ & $\mathrm{~B} 2$ & $1^{\mathrm{c}}$ \\
\hline Fluoranthene (FL) & 3 & $\mathrm{D}$ & 0.001 \\
\hline Fluorene (Flu) & 3 & $\mathrm{D}$ & 0.001 \\
\hline Indeno $[1,2,3-c, d]$ pyrene $(\operatorname{In}[c, d] \mathrm{P})$ & & & 0.1 \\
\hline Naphthalene (Nap) & $2 \mathrm{~B}$ & & 0.001 \\
\hline Perylene (PER) & 3 & & $0.001^{\mathrm{c}}$ \\
\hline Phenanthrene (PA) & 3 & $\mathrm{D}$ & 0.001 \\
\hline Pyrene (Pyr) & 3 & $\mathrm{D}$ & 0.001 \\
\hline
\end{tabular}

Cancer evidence and potency equivalency factor (PEF) for PAHs relative to $\mathrm{B}[a] \mathrm{P}$ (Nisbet and LaGoy, 1992) used in this study

${ }^{a}$ Classified by IARC (1987): 2A, probably carcinogenic to human (sufficient evidence for human cancer); 2B, possibly carcinogenic to human (sufficient evidence for animal cancer and possible evidence for human cancer); 3, not classifiable as to human and animals (inadequate evidence for animal cancer and evidence for mutagenicity).

b OEHHA (1993): B2, probably carcinogenic to human (inadequate evidence in human cancer and sufficient evidence in animal cancer); D, not classifiable as to human and animal (inadequate evidence in animal cancer).

c Value adopted from Malcolm and Dobson (1994). 
where $R_{\mathrm{D}}$ is the incremental individual lifetime cancer risk associated with dermal contact, $C_{\mathrm{pa}}$ is the particlebound PAH concentration $\left(\mu \mathrm{g} \mathrm{g}^{-1}\right), \mathrm{CSF}_{\mathrm{d}}$ is the carcinogenic slope factor for dermal contact $\left(\mathrm{mg} \mathrm{kg}^{-1} \mathrm{~d}^{-1}\right)^{-1}$, $\mathrm{AB}$ is the dermal adsorption fraction (dimensionless), $\mathrm{SA}$ is the dermal surface area exposed $\left(\mathrm{cm}^{2}\right), \mathrm{EV}$ is the event frequency (event $\mathrm{d}^{-1}$ ), and $\mathrm{AF}_{\mathrm{d}}$ is the particle-toskin adherence factor $\left(\mathrm{mg} \mathrm{cm}^{-2}\right.$ event $\left.^{-1}\right)$. We treated $C_{\mathrm{pa}}, \mathrm{BW}, \mathrm{AB}, \mathrm{SA}, \mathrm{AF}_{\mathrm{d}}$, and $\mathrm{EF}$ in Eq. (2) probabilistically. The total risk is the sum of risks associated with each exposure route.

The ILCRs for adult, adolescent, and child are calculated respectively as: For adult: ILCR $=\sum_{i=18}^{70} R_{i} / 53$, for adolescent: $\quad$ ILCR $=\sum_{i=12}^{17} R_{i} / 6$, and for child: $\mathrm{ILCR}=\sum_{i=1}^{11} R_{i} / 11$. An averaging time of $365 \mathrm{~d} \mathrm{year}^{-1}$ for 70 year (i.e., AT $=25550 \mathrm{~d}$ ) was used to characterize lifetime exposure for cancer risk calculation. The potency of $\mathrm{B}[a] \mathrm{P}$ is based on the $95 \%$ upper confidence limit of the linearized multistage model (OEHHA, 1993) applied to the incidence of respiratory tumors after inhalation exposure in hamsters (Thyssen et al., 1981). Collins et al. (1991) have estimated the cancer slope factor for $\mathrm{B}[a] \mathrm{P}$ inhalation exposure based on three different hamster inhalation rates of $0.037,0.063$, and $0.158 \mathrm{~m}^{3} \mathrm{~d}^{-1}$ and resulted in the CSF values of $6.1,3.8$, and $1.3\left(\mathrm{mg} \mathrm{kg}^{-1} \mathrm{~d}^{-1}\right)^{-1}$, respectively. We averaged those three CSF values and log-transformed appropriately to a lognormal distribution with a geometric mean $3.14\left(\mathrm{mg} \mathrm{kg}^{-1} \mathrm{~d}^{-1}\right)^{-1}$ and a geometric standard deviation 1.80 . For exposure to $\mathrm{B}[a] \mathrm{P}$ by dermal contact pathway, the potency of $37.47\left(\mathrm{mg} \mathrm{kg}^{-1} \mathrm{~d}^{-1}\right)^{-1}$ based on incidence of skin tumors in mice (Schmahl et al., 1977) can be used (Hussain et al., 1998). The cancer slope factors are normalized to account for extrapolation to a different body weight from standard of $70 \mathrm{~kg}$ (Eqs. (1) and (2)). The acceptable risk distribution was assigned by constraints on percentiles. The lower end of the range of acceptable risk distribution is defined by a single con- straint on the 95th percentile of risk distribution that must be equal or lower than $10^{-6}$ for carcinogens.

\subsection{Input probability distributions}

Current literature was reviewed to develop probability distributions for the random variables appearing in the risk models adopted. Exposure parameters have been considered random except exposure duration. Table 2 shows the selected type of probability distribution for random variables.

Having no site-specific data on population body weight, a second-order distribution was chosen for this parameter with the population age distribution in the Taiwan region used to estimate the population body weight and a lognormal distribution adopted whose parameters are expressed as a function of age separately for man and women (Burmaster and Crouch, 1997). Probability distributions chosen for the inhalation rate and for the skin surface area are based on the body weight distribution probability. Skin surface area is estimated by the relationship $\mathrm{SA}=a \cdot \mathrm{BW}^{b}$ where $a$ and $b$ are constants estimated by Burmaster (1998). The PAHs inhalation rate is given by the product of body weight and the weight specific inhalation rate used that is given in the ICRP66 (ICRP, 1994). In this probabilistic exposure assessment, only independent or correctly correlated random variables are considered.

\subsection{Uncertainty analysis}

To quantify this uncertainty and its impact on the estimation of expected risk, a Monte Carlo simulation was implemented. To test the convergence and the stability of the numerical output, we performed independent runs at 1000, 4000, 5000, and 10000 iterations with each parameter sampled independently from the appropriate distribution at the start of each replicate.

Table 2

Exposure parameters considered as random variables (lognormal distribution with geometric mean and geometric stand deviation: $\mathrm{LN}(\mathrm{gm}, \mathrm{gsd})$ ) for different age groups for temple residential setting

\begin{tabular}{|c|c|c|c|c|}
\hline \multirow[t]{2}{*}{ Exposure variable } & \multirow[t]{2}{*}{ Unit } & \multicolumn{3}{|c|}{ Lognormal distribution } \\
\hline & & Child, 1-11 year & Adolescent, 12-17 year & Adult, $18-70$ year \\
\hline Body weight $(\mathrm{BW})^{\mathrm{a}}$ & $\mathrm{kg}$ & $\mathrm{LN}(23.03,1.01)$ & $\mathrm{LN}(52.23,1.04)$ & $\mathrm{LN}(59.25,1.05)$ \\
\hline Inhalation rate $\left(\mathrm{IR}_{\mathrm{air}}\right)^{\mathrm{b}}$ & $\mathrm{m}^{3} \mathrm{~d}^{-1}$ & $\mathrm{LN}(14.10,1.72)$ & $\mathrm{LN}(32.13,1.04)$ & $\mathrm{LN}(32.73,1.14)$ \\
\hline Exposure frequency $(\mathrm{EF})^{\mathrm{c}}$ & d year ${ }^{-1}$ & $\mathrm{LN}(7.71,1.56)$ & $\mathrm{LN}(7.71,1.56)$ & $\mathrm{LN}(7.71,1.56)$ \\
\hline Dermal surface exposure $(\mathrm{SA})^{\mathrm{d}}$ & $\mathrm{cm}^{2}$ & $\mathrm{LN}(2792.53,1.01)$ & $\mathrm{LN}(4902.56,1.02)$ & $\mathrm{LN}(5333.33,1.03)$ \\
\hline Dermal adherence rate $\left(\mathrm{AF}_{\mathrm{d}}\right)^{\mathrm{e}}$ & $\mathrm{mg} \mathrm{cm}^{-2}$ event $^{-1}$ & $\mathrm{LN}(0.04,3.41)$ & $\mathrm{LN}(0.04,3.41)$ & $\mathrm{LN}(0.02,2.67)$ \\
\hline Dermal adsorption fraction $(\mathrm{AB})^{\mathrm{e}}$ & Dimensionless & $\mathrm{LN}(0.13,1.26)$ & $\mathrm{LN}(0.13,1.26)$ & $\mathrm{LN}(0.13,1.26)$ \\
\hline
\end{tabular}

\footnotetext{
a Adapted from Department of Health, ROC (http://www.doh.gov.tw/cht/index.aspx\#).

b Adapted from ICRP 66 (ICRP, 1994).

c Adapted from Ministry of Interior, ROC (2004).

d Adapted from USEPA (1987).

e Adapted from USEPA (2001).
} 
Largely because of limitations in the data used to derive model parameters, inputs were assumed to be independent. The result shows that 5000 iterations are sufficient to ensure the stability of results. Sensitivity analysis identified the most significant parameters that were included in the uncertainty and variability analysis.

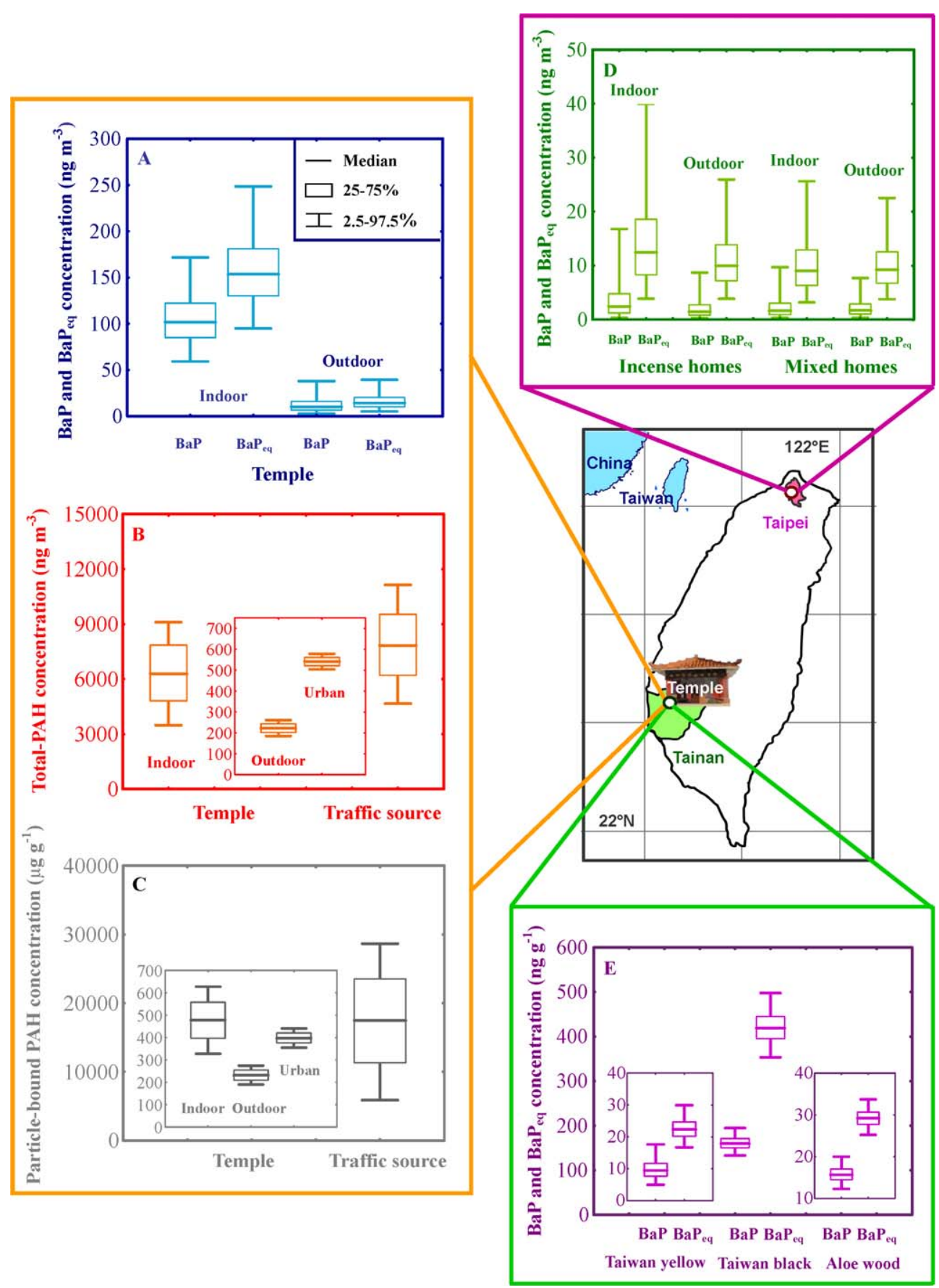

Fig. 1. Box and whisker plots of $(\mathrm{A}) \mathrm{B}[a] \mathrm{P}$ - and $\mathrm{B}[a] \mathrm{P}_{\mathrm{eq}}$-based concentrations in indoor/outdoor of temple, (B) total-PAH levels in indoor/outdoor of temple, urban area, and traffic-source, (C) particle-bound PAH level in indoor/outdoor of temple, urban area, and traffic-source, (D) $\mathrm{B}[a] \mathrm{P}$ - and $\mathrm{B}[a] \mathrm{P}_{\text {eq }}$-based concentrations in incense burning and mixed homes, and (E) $\mathrm{B}[a] \mathrm{P}-$ and $\mathrm{B}[a] \mathrm{P}_{\mathrm{eq}}-\mathrm{based}$ concentrations for three representative types of incense of Taiwan yellow, Taiwan black, and aloe wood. 
The sensitivity of each variable relative to one another was assessed by calculating rank correlation coefficients between each input and output during simulations and then estimating each input contribution to the output variance by squaring the output variance and normalizing to $100 \%$. The Monte Carlo simulation and sensitivity analysis were implemented using Crystal Ball software (Version 2000.2, Decisioneering, Inc., Denver, CO, USA).

\section{Results and discussion}

The median $\mathrm{B}[a] \mathrm{P}$ - and $\mathrm{B}[a] \mathrm{P}_{\text {eq }}$-based concentrations in temple are 101.8 and 153.61 ; and 10.22 and 14.31 $\mathrm{ng} \mathrm{m}^{-3}$ in indoor and outdoor, respectively (Fig. 1A), whereas the median particle-bound PAH concentrations are determined to be 478.4 and $232.47 \mathrm{ng} \mathrm{m}^{-3}$ for indoor and outdoor, respectively (Fig. 1C). The median $\mathrm{B}[a] \mathrm{P}-$ and $\mathrm{B}[a] \mathrm{P}_{\mathrm{eq}}$-based concentrations for three types incense are estimated to be 9.47 and $22.35 ; 159.9$ and 419.23; and 15.67 and $29.17 \mathrm{ng} \mathrm{g}^{-1}$, respectively, for Taiwan yellow, Taiwan black, and aloe wood (Fig. 1E). Our analysis also demonstrates that $\mathrm{B}[a] \mathrm{P}$ levels inside the temple were much higher than those measured inside residential homes in Taipei (Fig. 1A and D), whereas the total-PAH and particle-bound PAH levels were close to that measured at traffic-source and local urban area, respectively (Fig. 1B and C).

Probabilistic simulations of the risk models produced skewed probability density functions (pdfs) of predicted inhalation and dermal contact ILCRs (geometric standard deviations of lognormal distribution range from 2.5 to 3.33) (Fig. 2). Percentile predictions of ILCR personal exposure of three age groups could be determined from cumulative density functions (cdfs) corresponding to pdfs shown in Fig. 2. Under most regulatory program, an ILCR between $10^{-6}$ and $10^{-4}$ indicates potential risk, whereas ILCR larger than $10^{-4}$ indicates high potential health risk. Our results indicate that the $90 \%$ probability inhalation ILCRs for three age groups exposed to PAH inside the temple (Fig. 2A and B) and incense burning homes (Fig. 2E and F) have orders of magnitude around $10^{-7}$ and $10^{-6}$, respectively; whereas the dermal contact ILCRs for child, adolescent, and adult in the temple range from $10^{-5}$ to $10^{-4}$; indicating high potential carcinogenic risk (Fig. $2 \mathrm{C}$ and $\mathrm{D}$ ).

All $90 \%$ probabilities of $\mathrm{B}[a] \mathrm{P}-$ and $\mathrm{B}[a] \mathrm{P}_{\text {eq }}$-based total ILCRs (TILCRs) are large than $10^{-6}$, indicating unacceptable probability distributions for three age groups (Fig. 3). For adult personal exposure to carcinogenic PAH in the temple, $90 \%$ probability TILCR $\left(1.11 \times 10^{-4}-1.37 \times 10^{-4}\right)$ is much greater than the range of $10^{-6}-10^{-4}$, indicating high potential health risk; whereas for adolescent and child age groups, $90 \%$ probability TILCRs range from $6.13 \times 10^{-5}$ to $7.28 \times 10^{-5}$
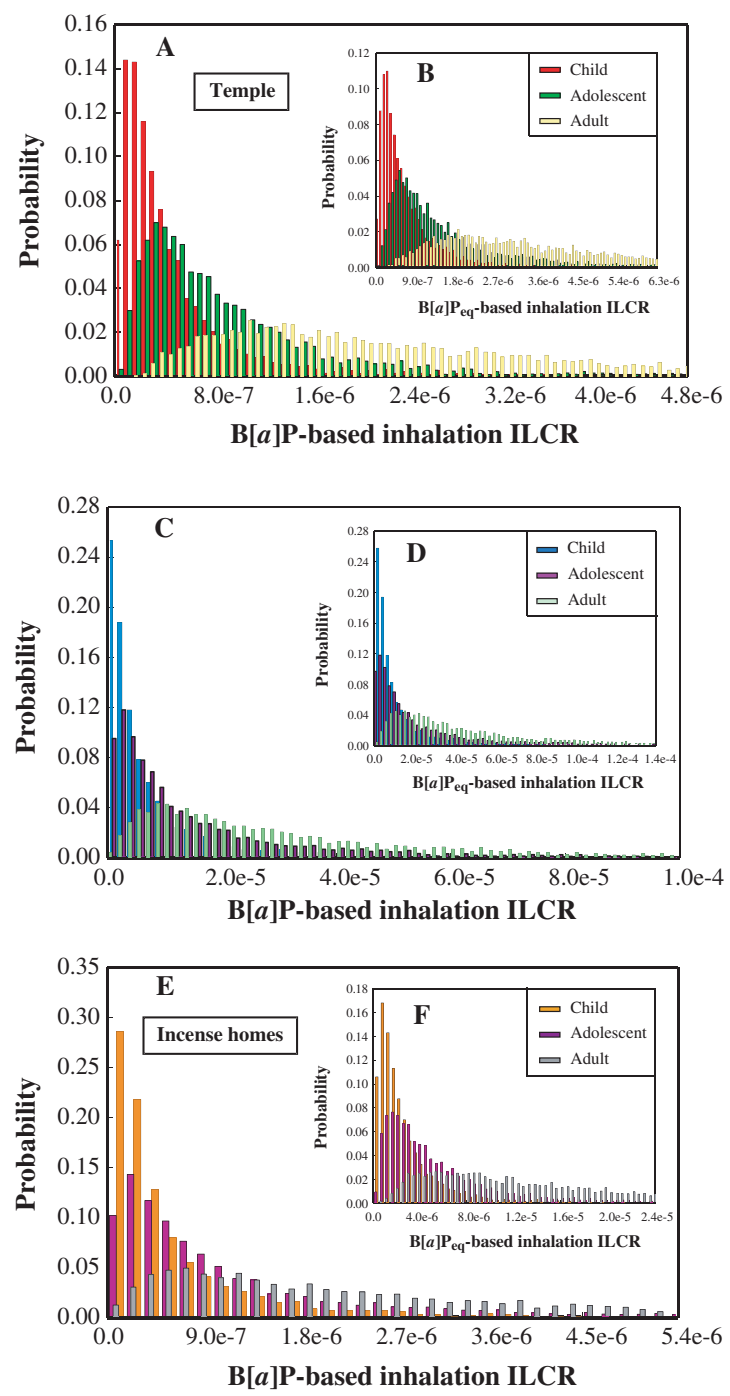

Fig. 2. Predicted probability density functions of $\mathrm{B}[a] \mathrm{P}$ - and $\mathrm{B}[a] \mathrm{P}_{\mathrm{eq}}$-based inhalation and dermal contact incremental lifetime cancer risks for three age groups in (A, B, C, D) temple and in $(\mathrm{E}, \mathrm{F})$ incense burning homes.

and $2.44 \times 10^{-5}$ to $3.03 \times 10^{-5}$, respectively (Fig. 3A), indicating potential health risk. Our risk analysis demonstrates that $\mathrm{B}[a] \mathrm{P}_{\mathrm{eq}}$-based approach predicted higher risks than that by $\mathrm{B}[a] \mathrm{P}$-based approach. The $\mathrm{B}[a] \mathrm{P}_{\mathrm{eq}^{-}}$ based approach, however, is necessarily limited to a few PAHs that have monitored in ambient air and dose not account for the toxicity of all PAHs to which the general population is exposed. Moreover, the additivity assumption of this approach is quite uncertain and may lead to inaccurate assessments. Despite this limitation, this approach has the merit of taking into account the actual PAH profiles encountered in the temple environment reported in this study. 


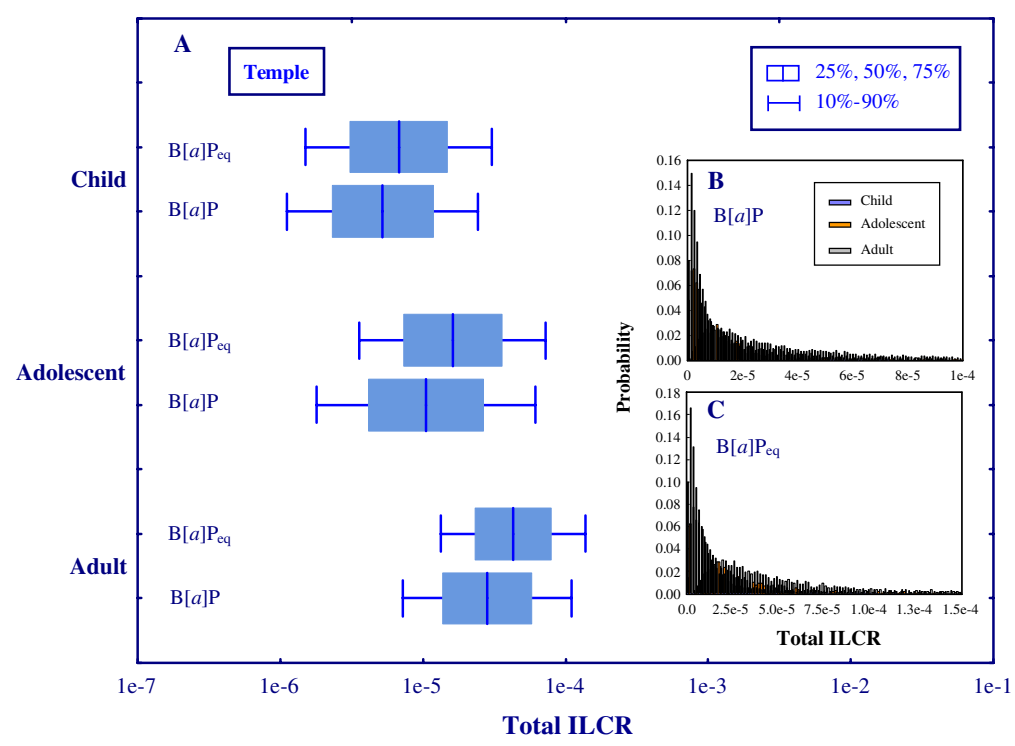

Fig. 3. (A) Box and whisker plots of total incremental lifetime cancer risks for three age groups based on $\mathrm{B}[a] \mathrm{P}-$ and $\mathrm{B}[a] \mathrm{P}$ eq exposure inside temple. Probability density functions of total incremental lifetime cancer risk for three age groups based on $\mathrm{B}[a] \mathrm{P}$ and $\mathrm{B}[a] \mathrm{P}_{\mathrm{eq}}$ exposure are also shown in (B) and (C).

(A) Inhalation ILCR
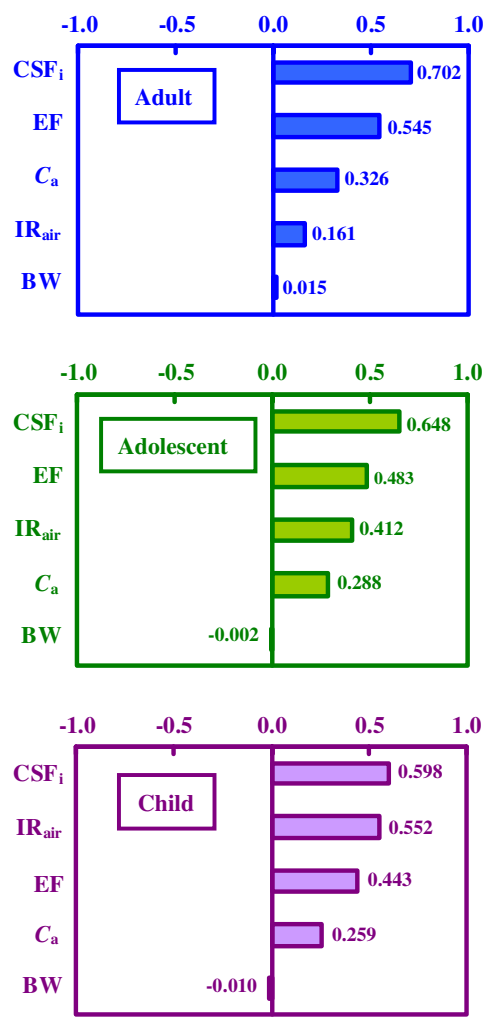

(B) Dermal contact ILCR
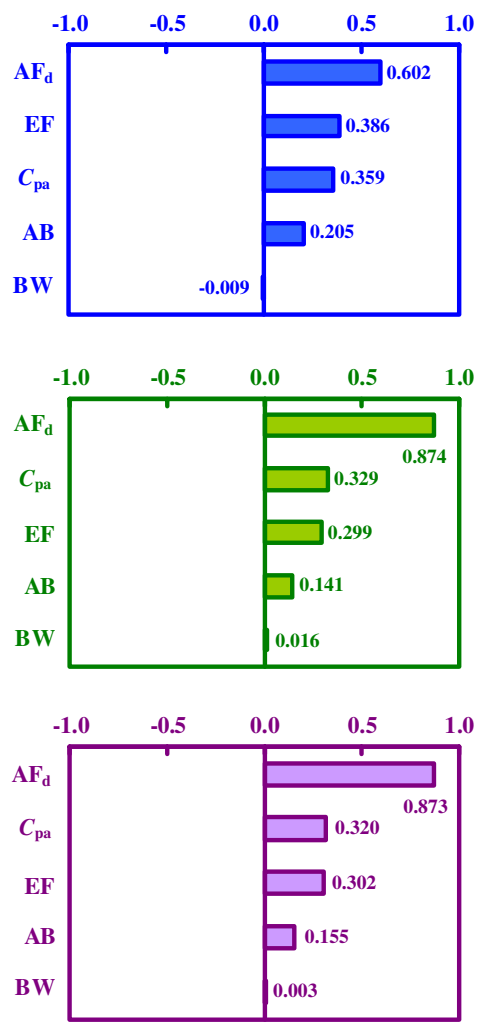

Fig. 4. Sensitivity analysis of (A) inhalation incremental lifetime risk model and (B) dermal contact incremental lifetime risk model for three age groups. 
A sensitivity analysis was performed to determine which pdfs have the greatest effect on risk estimates. The results of the sensitivity analyses on inhalation and dermal contact risk models are shown in the form of tornado plots illustrating the Spearman rank order correlation coefficients (Fig. 4). For inhalation exposure, the inhalation cancer slope factor $\left(\mathrm{CSF}_{\mathrm{i}}\right)$ and exposure frequency (EF) are the most influential variables for adult $(70 \%$ and $55 \%$, respectively) and adolescent $(65 \%$ and $48 \%$, respectively), whereas for child the most sensitive variables are $\mathrm{CSF}_{\mathrm{i}}$ and air inhalation rate $\left(\mathrm{IR}_{\text {air }}\right)$ $(60 \%$ and $55 \%$, respectively). For dermal exposure to particle-bound $\mathrm{PAH}$, the particle-to-skin adherence factor $\left(\mathrm{AF}_{\mathrm{d}}\right)$ is the most influential variable for all three age groups (60-87\%) (Fig. 4). Sensitivity analysis indicates that to increase the accuracy of the results efforts should focus on a better definition of probability distributions for inhalation cancer slope factor, inhalation rates, and particle-bound PAH-to-skin adherence factor. Given the scarcity of temple data, most of the probability distributions were based on US EPA data, and this may be a limitation to the validity of the case presented.

The CSF values (upper 95\% CI estimate of initial dose-response curve) for continuous inhalation exposure to $\mathrm{B}[a] \mathrm{P}$ obtained from several datasets (respiratory tract tumors in hamsters and gastric tumors in mice) by Collins et al. (1991) range between 1.3 and 16.9 $\left(\mathrm{mg} \mathrm{kg}^{-1} \mathrm{~d}^{-1}\right)^{-1}$ of $\mathrm{B}[a] \mathrm{P}$. The differences are due in part to the different treatment procedures and to assumptions adopted on animal physiological parameters (e.g., surface area scaling factor). Ingestion exposure data were used for inhalation exposure assessment by considering the intake dose with route-to-route extrapolation. It must also be noted that uncertainties are inherent in quantitative risk assessment because of assumptions required to extrapolate from one species to another, from high to low situations and because of the statistical modeling techniques required to fit data points. Extrapolation to low doses and the transferring of results from test animals to humans is not evident at all. Therefore, rodent-derived risk factors may have different orders of magnitude comparing with empirical data derived risk estimates.

We calculated a risk-based visiting frequency advice $\left(\right.$ year $\left.^{-1}\right)$ and a suggested amount of incense burning associated to unit occupied volume of temple based on a maximum acceptable individual lifetime risk level of $10^{-6}$. Our results indicate that the $\mathrm{B}[a] \mathrm{P}_{\text {eq }}$ and $\mathrm{B}[a] \mathrm{P}-$ based $90 \%$ probability visiting frequency for adult, adolescent, and child to a temple range from 5 to 7,17 to 23 , and 48 to 65 year $^{-1}$, respectively, based on an average $3 \mathrm{~h}$ residence time (Fig. 5A). The estimated suggested $90 \%$ probability incense burning amount for three representative incense types of Taiwan yellow, Taiwan black, and aloe wood range from 16.80 to $42.84,0.86$ to 2.32 , and 12.63 to $24.08 \mathrm{~g} \mathrm{~m}^{-3}$, respectively, based on $\mathrm{B}[a] \mathrm{P}_{\mathrm{eq}^{-}}$and
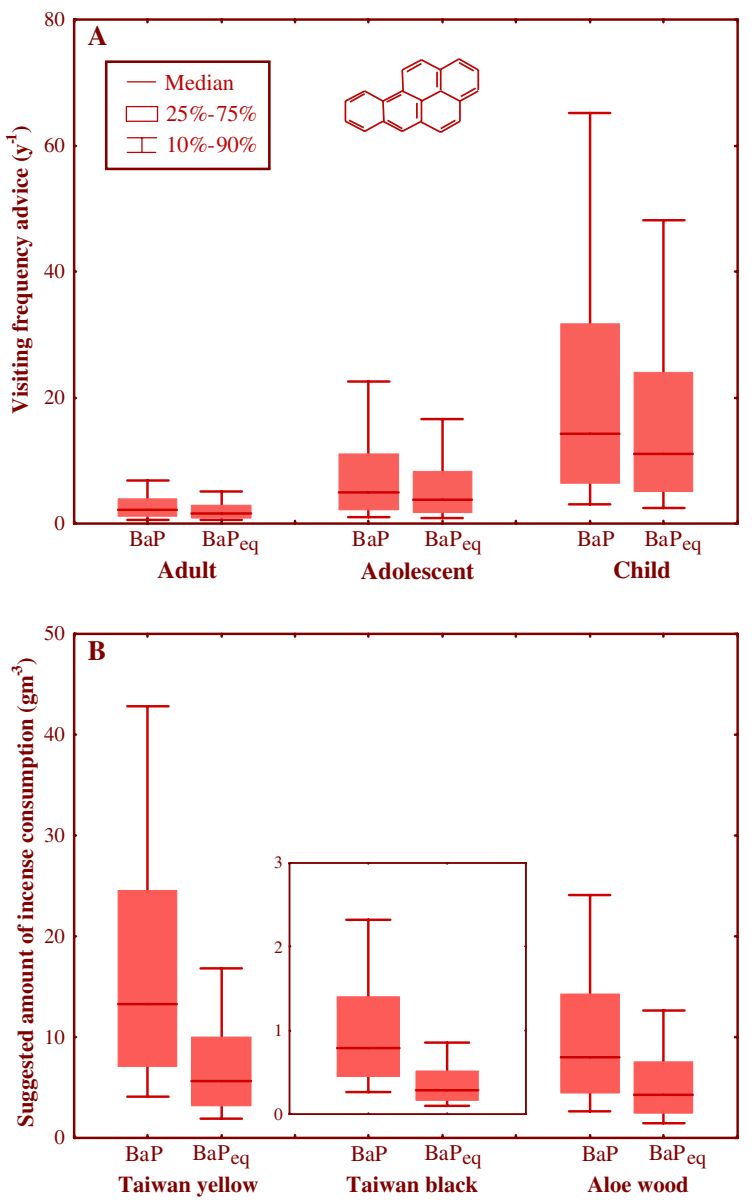

Fig. 5. Box and whisker plots of (A) estimated risk-based exposure frequency advice for three age groups visiting a temple and (B) estimated suggested amount of incense consumption for three types of incense of Taiwan yellow, Taiwan black, and aloe wood.

$\mathrm{B}[a]$ P-based calculation (Fig. 5B). The ILCR models associated to a unit airborne PAH concentration $\left(1 \mathrm{ng} \mathrm{m}^{-3}\right)$ or a unit particle-bound PAH concentration $\left(1 \mu \mathrm{g} \mathrm{g}^{-1}\right)$ inside the temple can be used to calculate the probabilistic unit exposure frequency based on a maximum allowable risk of $10^{-6}$ (Table 3). Therefore, the expected exposure frequency advice for a specific-age group is equal to the probabilistic unit suggested exposure frequency listed in Table 3 divided by the measured airborne PAH concentrations inside the temple concerned.

The carcinogenic risk assessment of PAH remains difficult, particularly due to the very high number of these compounds (in the hundreds) present in mixtures to which the general population may be exposed, as well as due to the possible contemporary presence of other risk factors and to possible synergistic and/or antagonistic effects. The choice of $\mathrm{B}[a] \mathrm{P}$ as the reference compound to develop the PEF is presently questioned 
Table 3

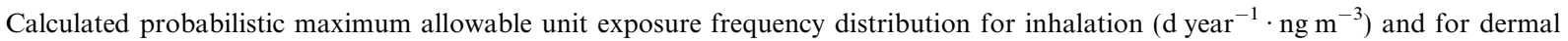
contact $\left(\mathrm{d}_{\text {year }}{ }^{-1} \cdot \mu \mathrm{g} \mathrm{g}^{-1}\right)$ for three age groups for visiting a typical temple

\begin{tabular}{llll}
\hline Exposure route & \multicolumn{4}{l}{ Probabilistic unit exposure frequency } & Adult, 18-70 year \\
\cline { 2 - 4 } & Child, 1-11 year & Adolescent, 12-17 year & $\mathrm{LN}(401.37,1.85)$ \\
\hline Inhalation & $\mathrm{LN}(3456.95,2.23)^{\mathrm{a}}$ & $\mathrm{LN}(1114.85,2.04)$ & $\mathrm{LN}(43.59,2.49)$ \\
Dermal contact & $\mathrm{LN}(283.15,3.44)$ & $\mathrm{LN}(99.54,3.44)$ & \\
\hline
\end{tabular}

${ }^{\text {a }}$ Lognormal distribution with a geometric mean and a geometric standard deviation.

(Goldstein, 2001). Due to the limited number of doseresponse data on carcinogenicity, and depending on the exposure route (intratracheal administration, intrapulmonary injection, and so on), different PEFs can be obtained. For example, the PEF value used in this study for $\mathrm{DB}[a, h] \mathrm{A}$ is 1.0 , as given by Malcolm and Dobson (1994). This value may underestimate the relevance of this compound, because other authors claim a PEF of 5.0 (Nisbet and LaGoy, 1992). It has also to be remembered that the $\mathrm{B}[a] \mathrm{P}_{\text {eq }}$ concentrations used for this calculation represent an external exposure estimation of carcinogenic compounds and not the effective active concentration at the lung level.

The case of the temple site is one of the first in Taiwan where a probabilistic analysis has been applied to personal exposure to carcinogenic PAHs. The regulatory agency in charge of public health protection should be aware that the deterministic risk analysis conceals issues relative to the probabilistic concept of risk. In fact, through requiring more resources and skills, a Monte Carlo exposure analysis carried out was very informative since it revealed the degree of conservatism and took into account the reliability of results.

\section{References}

Alexandrov, K., Cascorbi, I., Rojas, M., Bouvier, G., Kriek, E., Bartsch, H., 2002. CYP1A1 and GSTM1 genotypes affect benzo[ $a]$ pyrene DNA adducts in smokers' lung: comparison with aromatic/hydrophobic adduct formation. Carcinogenesis 23, 1969-1977.

Armstrong, B., Hutchinson, E., Unwin, J., Fletcher, T., 2004. Lung cancer risk after exposure to polycyclic aromatic hydrocarbons: a review and meta-analysis. Environ. Health Perspect. 112, 970-978.

ATSDR, 1990. Toxicological profile for benzo $[a]$ pyrene. Agency for Toxic Substance and Disease Registry, United States Public Health Service, Atlanta, GA.

Boffetta, P., Jourenkova, N., Gustavsson, P., 1997. Cancer risk from occupational and environmental exposure to polycyclic aromatic hydrocarbons. Cancer Causes Control 8, 444-472.

Burmaster, D.E., 1998. Lognormal distributions for skin area as a function of body weight. Risk Anal. 18, 27-32.

Burmaster, D.E., Crouch, E.A.C., 1997. Lognormal distributions for body weight as a function of age for males and females in the United States, 1976-1980. Risk Anal. 17, 499-505.

Collins, J.F., Brown, J.P., Alexeeff, GV., Salmon, A.G, 1998. Potency equivalency factors for some polycyclic aromatic hydrocarbons and polycyclic aromatic hydrocarbon derivatives. Regul. Toxicol. Pharmacol. 28, 45-54.

Collins, J.P., Brown, J.P., Dawson, S.V., Marty, M.A., 1991. Risk assessment for benzo[a]pyrene. Regul. Toxicol. Pharmacol. 13, 170-184.

Deutsch-Wenzel, R.P., Brune, H., Grimmer, G., Dettbarn, G., Misfeld, J., 1983. Experimental studies in rat lungs on the carcinogenicity and dose-response relationships of eight frequently occurring environmental polycyclic aromatic hydrocarbons. J. Natl. Cancer Inst. 71, 539-544.

Gaspari, L., Chang, S.S., Santella, R.M., Garte, S., Pedotti, P., Taioli, E., 2003. Polycyclic aromatic hydrocarbon-DNA adducts in human sperm as a marker of DNA damage and infertility. Mutat. Res. Genet. Toxicol. Environ. Mutagen. 535, 155-160.

Goldstein, L.S., 2001. To BaP or not to BaP? That is the question. Environ. Health Perspect. 109, A356-A357.

Hussain, M., Rae, J., Gilman, A., Kauss, P., 1998. Lifetime health risk assessment from exposure of recreational users to polycyclic aromatic hydrocarbons. Arch. Environ. Contain. Toxicol. 35, 527-531.

IARC, 1987. In Overall Evaluations of Carcinogenicity: An Updating of IARC Monographs, vols. 1-42, IARC Monographs on the Evaluation of Carcinogenic Risks to Humans, Supplement 7. International Agency for Research on Cancer, World Health Organization, Lyon.

International Commission on Radiological Protection (ICRP), 1994. Human Respiratory Tract Model for Radiological Protection. Elsevier, New York, NY.

Lee, W.J., Wang, Y.F., Lin, T.C., Chen, Y.Y., Lin, W.C., Ku, C.C., Cheng, J.T., 1995. PAH characteristics in the ambient air of traffic-source. Sci. Total Environ. 159, 185200.

Li, C.S., Ro, Y.S., 2000. Indoor characteristics of polycyclic aromatic hydrocarbons in the urban atmosphere of Taipei. Atmos. Environ. 34, 611-620.

Li, D., Wang, M., Cheng, L., Spitz, M.R., Hittelman, W.N., Wei, Q., 1996. In vitro induction of benzo[a]pyrene diol epoxide-DNA adducts in peripheral lymphocytes as a susceptibility marker for human lung cancer. Cancer Res. 56, 3638-3641.

Lin, T.C., Chang, F.H., Hsieh, J.H., Chao, H.R., Chao, M.R., 2002. Characteristics of polycyclic aromatic hydrocarbons and total suspended particulate in indoor and outdoor atmosphere of a Taiwanese temple. J. Hazard. Mater. A95, $1-12$. 
Lung, S.C.C., Kao, M.C., Hu, S.C., 2003. Contribution of incense burning to indoor $\mathrm{PM}_{10}$ and particle-bound polycyclic aromatic hydrocarbons under two ventilation conditions. Indoor Air 13, 194-199.

Malcolm, H.M., Dobson, S., 1994. The Calculation of an Environmental Assessment Level (EAL) for Atmospheric PAHs Using Relative Potencies. Department of the Environment, London, UK, pp. 34 46.

Nisbet, I.C.T., LaGoy, P.K., 1992. Toxic equivalency factors (TEFs) for polycyclic aromatic hydrocarbons (PAHs). Regul. Toxicol. Pharmacol. 16, 290-300.

Office of Environmental Health Hazard Assessment (OEHHA), 1993. Benzo[ $a]$ pyrene as a toxic air contaminant. Part B: health effects of benzo[ $[a]$ pyrene, Berkeley, CA.

Perera, F., Hemminki, K., Jedrychowski, W., Whyatt, R., Campbell, U., Hsu, Y., Santella, R., Albertini, R., O'Neill, J.P., 2002. In utero DNA damage from environmental pollution is associated with somatic gene mutation in newborns. Cancer Epidemiol. Biomarkers Prev. 11, 1134 1137.
Schmahl, D., Schmidt, K.G., Habs, M., 1977. Syncarcinogenic action of polycyclic aromatic hydrocarbons in automobile exhaust gas condensates. IARC Scientific Publication 16, WHO, Lyon, France.

Somers, C.M., Yauk, C.L., White, P.A., Parfett, C.L.J., Quinn, J.S., 2002. Air pollution induces heritable DNA mutations. Proc. Natl. Acad. Sci. USA 99, 15904-15907.

Thyssen, J., Althoff, J., Kimmerle, G., Mohr, U., 1981. Inhalation studies with benzo[a]pyrene in Syrian golden hamsters. J. Natl. Cancer Inst. 66, 575-577.

Tseng, K.C., 1996. Polycyclic aromatic hydrocarbons from burning raw materials for a Chinese incense. Master thesis. National Taiwan University, Taipei, Taiwan.

USEPA, 1987. Pesticide assessment guidelines for pesticides. Rev. Environ. Contam. Toxicol. 129, 79-93.

USEPA, 2001. Risk Assessment Guidance for Superfund, vol. I, Human Health Evaluation Manual (Part E, supplemental guidance for dermal risk assessment). EPA/540/R/99/005. Office of Emergency and Remedial Response, US Environmental Protection Agency, Washington, DC. 